\title{
PERAN PERCEIVED STRESS DAN SELF-EFFICACY TERHADAP TEACHER BURNOUT GURU TK PADA MASA PANDEMI COVID-19
}

\author{
Supi Catur Nadyastuti ${ }^{1}$, Heni Mularsih $(\text { Almh })^{2}$, Sri Tiatri $^{3}$ \\ ${ }^{1}$ Program Studi Magister Psikologi Sains, Universitas Jakarta \\ Email: supi.707191002@stu.untar.ac.id \\ ${ }^{2}$ Fakultas Psikologi, Universitas Tarumanagara \\ Email:henim@mku.untar.ac.id \\ ${ }^{3}$ Program Studi Magister Psikologi, Universitas Tarumanagara \\ Email: sri.tiatri@untar.ac.id
}

Masuk: 12-06-2021, revisi: 26-09-2021, diterima untuk diterbitkan: 09-10-2021

\begin{abstract}
This study aims to determine whether there is a role for perceived stress and self-efficacy on kindergarten teacher burnout in Jakarta during the Covid-19 pandemic. This research uses a quantitative approach and multiple linear regression analysis. This study uses the MBI-ES (Maslach Burnout Inventory-Educators Survey) measuring instrument developed by Maslach and Jackson (1996) to measure teacher burnout, and the PSS (Perceived Stress Scale) measurement tool developed by Cohen (1983) is used to measure perceived stress. Meanwhile, to measure teachers' self-efficacy against teacher burnout, the GSES (General Self-Efficacy Scale) measurement tool was used which was built following Bandura's social cognitive theory (Bandura, 1997), developed by Schwarzer and Jerusalem, 1995. The subjects of this study were 362 teachers from public and private kindergartens in Jakarta. The results of this study have a very significant relationship between perceived stress and self-efficacy variables on teacher burnout of kindergarten teachers in Jakarta during the Covid-19 pandemic. $p=0.000(p<0.01)$. The R square is 0.927 which when proxied $(0.927 \times 100 \%=92.7 \%)$ means that the amount of perceived stress and self-efficacy towards teacher burnout was $92.7 \%$ and the remaining $7.3 \%$ was influenced by other factors not examined in this study.
\end{abstract}

Keywords: Teacher burnout, perceived stress, self-efficacy, kindergarten teachers, the Covid-19 pandemic

\begin{abstract}
ABSTRAK
Penelitian ini bertujuan untuk mengetahui apakah ada peran perceived stress dan self-efficacy terhadap teacher burnout guru TK di Jakarta pada masa pandemi Covid-19. Penelitian ini menggunakan pendekatan kuantitatif dan analisis regresi linear berganda. Menggunakan alat ukur MBI-ES (Maslach Burnout Inventory-Educators Survey) yang dikembangkan oleh Maslach dan Jackson (1996) untuk mengukur teacher burnout, dan alat ukur PSS (Perceived Stress Scale) yang dikembangkan oleh Cohen (1983) untuk pengukuran perceived stress. Sedangkan untuk mengukur self-efficacy terhadap teacher burnout digunakan alat ukur GSES (General Self-Efficacy Scale) yang dibangun mengikuti teori kognitif sosial Bandura (Bandura, 1995), dikembangkan oleh Schwarzer dan Jerusalem (1995). Subjek penelitian ini adalah 362 guru dari TK Negeri dan Swasta di Jakarta. Hasil dari penelitian ini terdapat hubungan yang sangat signifikan antar variabel perceived stress dan self efficacy terhadap teacher burnout guru TK di Jakarta pada masa pandemi Covid-19. Hal tersebut ditunjukkan dengan diperoleh nilai $F=2264,757$ dengan $p=0,000(p<0,05) . R$ square sebesar 0,927 yang apabila dipresentasikan $(0,927 \times 100 \%=92,7 \%)$ artinya besar sumbangan perceived stress dan self-efficacy terhadap teacher burnout sebesar $92,7 \%$ dan sisanya $7,3 \%$ dipengaruhi oleh faktor lain yang tidak diteliti dalam penelitian ini.
\end{abstract}

Kata Kunci: Teacher burnout, perceived stress, self-efficacy, guru TK, pandemi Covid-19

\section{PENDAHULUAN}

\section{Latar Belakang}

Wabah pandemi Covid-19 yang menimpa lebih dari 200 negara di dunia berdampak sistemik terhadap kehidupan manusia mulai dari terguncangnya ekonomi, kesehatan, keamanan, dan juga pendidikan. Perubahan metode pembelajaran luar jaringan (tatap muka di kelas) menjadi dalam jaringan (pembelajaran jarak jauh) yang terjadi secara tiba-tiba, menimbulkan beberapa kendala dan tuntutan baru pemicu stress kerja pada guru. Diantaranya seperti kendala waktu belajar yang 
tidak menentu, pembelian kuota internet tambahan, kebiasaan baru dalam penggunaan teknologi sebagai media belajar (pengelolaan kelas online), sistem baru penilaian dan pelaporan hasil belajar siswa, serta tuntutan kerjasama dan komunikasi yang lebih baik dengan orang tua sebagai pendamping anak belajar di rumah (Husna, 2020).

Dalam sebuah penelitian yang dilakukan di New York, dilaporkan telah muncul banyak bukti menguatkan bahwa selama pandemi Covid-19, telah terjadi tekanan pada guru baik secara pribadi, terkait pekerjaan dan daya tanggap emosional mereka, yang secara tidak langsung memengaruhi proses pembelajaran. Beberapa guru bahkan mengaku mengalami reaksi emosi kemarahan, agresi, kecemasan, penarikan diri dari interaksi sosial, dan penurunan kompetensi sosial secara keseluruhan (Nagasawa \& Tarrant, 2020). Perubahan perilaku ini sesuai dengan gejala yang mengarah kepada kemungkinan gejala burnout. Tanda-tanda kemungkinan burnout guru, juga terlihat pada tingkat ketidakhadiran yang tinggi, masalah kelelahan dan sulit beristirahat (tidur), terjadinya perubahan perilaku seperti menarik diri dari interaksi sosial, perubahan penampilan (meningkat dan menurunnya berat badan secara drastis) dan kesadaran kebersihan pribadi yang menurun (Schaffhauser, 2020).

Burnout adalah sebuah sindrom kelelahan emosional (emotional exhaustion), depersonalisasi (depersonalization), dan penurunan prestasi pribadi (reduced personal accomplishment) yang dapat terjadi di antara individu yang bekerja dengan orang lain dalam "kapasitas tertentu" (Maslach et al., 1996, dalam Maslach, 2008). Tekanan psikologis yang demikian sering mengakibatkan ketidakpuasan, ketidakhadiran, dan pergantian karyawan di kalangan guru sekaligus memunculkan perilaku merugikan yang bersifat psikologis (kecemasan dan depresi), fisiologis, atau perilaku gaya hidup, dan masalah tidur yang selanjutnya mengarah pada pengembangan burnout di antara para guru (Friedman-Krauss et al., 2014; Lian et al., 2014; Roeser et al., 2013; Torsheim \& Wold, 2001 dalam Yu et al., 2015).

Faktor-faktor yang berpengaruh terhadap sindrom burnout seorang guru menurut beberapa studi dan literatur sebelumnya, diketahui adalah perceived stress dan self-efficacy (Betoret, 2009; Cheng, 2008; Hartawati \& Mariyanti, 2014; Herman et al., 2017; Maryati \& Mustika, 2016; McLean et al., 2019; Yu et al., 2015; Zhu et al., 2018).

Perceived stress merupakan tekanan psikologis atau stress yang terjadi ketika individu merasa bahwa tuntutan lingkungan melebihi kemampuan adaptasi individu tersebut dan bagaimana individu memaknainya (Cohen, 2007). Salah satu faktor bagaimana meminimalkan burnout adalah perceived stress harus dikelola dengan baik, jika stress segera diatasi, kondisi dan gejala yang mengarah kepada burnout itu tidak akan bertahan lama.

Self-efficacy dapat diartikan sebagai keyakinan individu mengenai kemampuan dirinya dalam melakukan tugas atau tindakan yang diperlukan untuk mencapai hasil tertentu (Bandura, 1997). Kini teori self-efficacy semakin banyak digunakan oleh para peneliti dalam beberapa tahun terakhir untuk mempelajari burnout serta untuk mengeksplorasi peran self-efficacy terhadap burnout. Selain itu, penelitian lain juga menemukan bahwa self-efficacy guru adalah hasil dari burnout mereka, dan faktor tersebut berfungsi sebagai tindakan korektif untuk burnout (Egyed \& Short, 2006 dalam Yu et al., 2015).

Diketahui, penelitian tentang tingkat stress pada guru pra sekolah sebelumnya juga pernah dilakukan oleh Hozo et al. (2015), dengan judul "Sindrom Burnout pada Guru Lembaga PraSekolah." Pengukuran tingkat stress dilakukan menggunakan kuesioner oleh Girdin et al. (1996) 
pada 100 guru TK Radost (Joy) di Kota Split-Italia sepanjang tahun 2014. Hasil penelitian menunjukkan bahwa tidak ada perbedaan jumlah yang signifikan antara guru TK yang merasa baik-baik saja, dengan guru TK yang mengalami sindrom burnout.

Berdasarkan penelitian sebelumnya di atas, maka tampak ada gap penelitian, yaitu ada penelitian yang hasil temuannya menunjukkan ada hubungan antara stress dan self-efficacy dengan burnout (Herman et al., 2017; Maryati \& Mustika, 2016; Yu et al., 2015; Zhu et al., 2018) dan ada penelitian yang hasilnya tidak ada hubungan (Hozo et al., 2015).

Gap ini menimbulkan keraguan sehingga menjadi dasar untuk dilakukannya penelitian ulang. Selain itu, dalam penelitian ini ada beberapa perbedaan mendasar dengan penelitian sebelumnya. Salah satu perbedaan yang cukup signifikan adalah situasi kondisi yang saat ini sedang berlangsung, penelitian sebelumnya dilakukan pada saat keadaan normal dengan metode pembelajaran tatap muka langsung di dalam kelas, sedangkan penelitian ini dilakukan pada saat kondisi luar biasa, yaitu pada masa pandemi Covid-19 dengan penerapan metode pembelajaran jarak jauh (PJJ).

Berdasarkan permasalahan di atas, dan mengamati fenomena yang terjadi, maka peneliti tertarik melakukan penelitian untuk mengetahui peran perceived stress dan self-efficacy terhadap teacher burnout Guru TK di Jakarta pada masa pandemi Covid-19.

\section{Rumusan Masalah}

Berdasarkan latar belakang masalah maka perumusan masalah dalam penelitian ini adalah "Apakah ada peran perceived stress dan self-efficacy terhadap teacher burnout Guru TK di Jakarta pada Masa Pandemi Covid-19?"

\section{METODE PENELITIAN}

\section{Partisipan penelitian}

Partisipan dalam penelitian ini adalah guru TK di wilayah Jakarta, yang melakukan kegiatan pembelajaran jarak jauh pada masa pandemi Covid-19. Tidak terdapat batasan usia, jenis kelamin, agama, suku, maupun ras dalam penelitian ini. Jumlah partisipan dalam penelitian ini ri 362 guru terdiri dari guru TK Negeri Negeri dan Swasta di Jakarta. Metode pengumpulan data penelitian ini menggunakan kuesioner. Penelitian ini menggunakan kuesioner dengan pertanyaan tertutup menggunakan skala likert. Pengumpulan data dilakukan secara online disebabkan kondisi Jakarta pada saat dilakukannya pengambilan data masih dalam situasi pembatasan sosial berskala besar (PSBB).

Pengukuran dalam penelitian menggunakan (a) skala teacher burnout menggunakan alat ukur "Maslach Burnout Inventory-Educators Survey/MBI-ES" (dikembangkan menurut MBI-ES, Maslach dan Jackson pada tahun 1996)". Kuesioner terdiri dari 22 butir pernyataan, model skala pengukuran menggunakan model skala likert dengan item-item dalam skala ini merupakan pernyataan seberapa sering dengan enam pilihan jawaban. Mulai dari skala 0 adalah tidak pernah sampai dengan skala 6 adalah setiap hari pada masa pandemi Covid-19; (b) skala perceived stress menggunakan alat ukur "Perceived Stress Scale" (PSS) dikembangkan oleh Cohen pada tahun 1983. Kuesioner ini terdiri dari 10 butir pernyataan, model skala pengukuran menggunakan model skala likert, dari skala 1 hingga 5. Item-item dalam skala ini merupakan pernyataan seberapa sering perasaan itu muncul, dengan 5 pilihan jawaban yaitu tidak pernah, hampir tidak pernah, kadangkadang, hampir sering, dan sangat sering; (c) skala self-efficacy menggunakan alat ukur General 
Self-Efficacy Scale (GSES) yang dibangun mengikuti teori kognitif sosial Bandura (Bandura, 1997; Schwarzer, 1992, 1993), dikembangkan oleh Schwarzer dan Jerusalem, tahun 1995. Telah diterjemahkan dalam Bahasa Indonesia dan melalui uji validitas konstruk instrumen dengan hasil bahwa keseluruhan item GSES berjumlah 10 pernyataan, model skala pengukuran menggunakan model skala likert, dari skala 1 hingga 4. Item-item dalam skala ini untuk menggambarkan seberapa sering perasaan itu muncul, dengan 4 pilihan jawaban yaitu STS (Sangat Tidak Sesuai), TS (Tidak Sesuai), CS (Cukup Sesuai), SS (Sangat Sesuai) (Schwarzer and Jerusalem 1995; Weber et al. 2013 dalam Yu et.al., 2015).

Uji asumsi yang dilakukan terlebih dahulu sebelum dilakukan uji hipotesis, yaitu uji normalitas. Lalu peneliti melakukan uji regresi linear untuk melihat prediksi variabel independent terhadap variabel dependent. Terakhir peneliti melakukan uji regresi berganda atau multiple regression untuk melihat seberapa besar sumbangan variabel perceived stress dan self-efficacy terhadap teacher burnout guru TK. Seluruh analisis data menggunakan program komputer, yaitu Statistical Packages for Social Sciences (SPSS) versi 22 untuk windows. Teknik analisis data yang digunakan untuk menguji hipotesis penelitian adalah teknik analisis regresi linier berganda, yaitu tiga variabel yang masing masing datanya berwujud skor.

\section{HASIL DAN PEMBAHASAN}

Penelitian ini dilakukan pada 362 guru aktif TK Negeri dan Swasta di Jakarta yang melakukan metode Pembelajaran Jarak Jauh (PJJ) pada masa pandemi Covid-19.

\section{Tabel 1}

Gambaran Partisipan Berdasarkan Jenis Kelamin

\begin{tabular}{ccc}
\hline Jenis Kelamin & Jumlah & Persentase (\%) \\
\hline Wanita & 329 & 90.9 \\
\hline Pria & 33 & 9,1 \\
\hline Total & 362 & 100
\end{tabular}

Berdasarkan tabel di atas diketahui bahwa pada penelitian ini jumlah partisipan wanita lebih banyak dibandingkan partisipan pria, yakni 90,9\% dari total partisipan atau sebanyak 329 responden. Sedangkan sisanya sebanyak $9,1 \%$ atau sebanyak 33 responden berjenis kelamin pria.

\section{Tabel 2}

Gambaran Partisipan Berdasarkan Usia

\begin{tabular}{ccc}
\hline Umur (tahun) & Jumlah & Persentase (\%) \\
\hline Dewasa Muda (20-39) & 324 & 89.5 \\
\hline Dewasa Madya (40-65) & 38 & 10,5 \\
\hline Total & 362 & 100 \\
\hline
\end{tabular}

Berdasarkan tabel 2, diketahui bahwa partisipan pada penelitian ini didominasi oleh guru-guru yang berusia sekitar 20 hingga 39 tahun atau dalam kategori dewasa muda (Papalia et al., 2009 dalam Dewi et al., 2019) yakni sekitar 89,5\% dan sisanya dewasa madya (paruh baya) sebanyak $10,5 \%$. 
Untuk menguji hipotesis mayor digunakan analisis regresi. Berdasarkan hasil analisis data diketahui bahwa besarnya pengaruh antara variabel perceived stress dan self-efficacy terhadap teacher burnout diperoleh skor $\mathrm{F}=2264,757$ dengan $\mathrm{p}<0,05$ sehingga hipotesis nihil diterima. Hal ini menunjukkan bahwa terdapat hubungan yang sangat signifikan antara variabel perceived stress dan self-efficacy terhadap variabel teacher burnout guru TK di Jakarta pada masa pandemi Covid19. Hasil analisis dapat dilihat pada tabel 3.

\section{Tabel 3}

Hasil Uji Analisis Secara Simultan

\begin{tabular}{ccccc}
\hline Hipotesis & $\mathbf{F}$ & $\mathbf{R}^{\mathbf{2}}$ & Sig (p) & Keterangan \\
\hline $\begin{array}{l}\mathrm{X}_{1} \text { dan } \mathrm{X}_{2} \\
\text { dengan Y }\end{array}$ & 2264,757 & 0,927 & 0,000 & Sangat \\
& & & & Signifikan \\
\hline
\end{tabular}

Hasil analisis data secara parsial dapat dilihat pada tabel 4 di bawah ini:

Tabel 4

Hasil Analisis Secara Parsial

\begin{tabular}{ccc}
\hline Variabel & Beta & Signifikansi \\
\hline Perceived stress dengan teacher burnout & 0,961 & 0,000 \\
\hline Self-efficacy dengan teacher burnout & $-0,868$ & 0,000 \\
\hline
\end{tabular}

Data yang diperoleh dari hasil analisis data pada tabel 4 diketahui bahwa besarnya peranan variabel perceived stress dengan teacher burnout diperoleh skor beta $=0,961$ dengan nilai $\mathrm{p}<0,01$ sehingga hipotesis minor pertama dapat diterima. Hal ini menunjukkan bahwa terdapat peran yang sangat signifikan antara perceived stress terhadap teacher burnout. Peran self efficacy terhadap teacher burnout diperoleh skor beta $=-0,868$ dengan nilai $\mathrm{p}<0,01$ sehingga hipotesis minor kedua diterima. Hal tersebut menunjukkan ada peran yang sangat signifikan antara self efficacy terhadap teacher burnout.

Berdasarkan uji statistik di atas, hipotesis minor yang diajukan teruji kebenarannya. Hal ini menunjukkan ada peran yang sangat signifikan antara perceived stress dan self-efficacy terhadap teacher burnout guru TK di Jakarta pada masa Pandemi Covid-19, yang berarti semakin tinggi perceived stress, semakin tinggi teacher burnout yang dimiliki oleh guru TK di Jakarta pada masa pandemi Covid-19 dan semakin rendah self-efficacy, semakin tinggi teacher burnout yang dimiliki oleh guru TK di Jakarta pada masa pandemi Covid-19.

Artinya, hasil penelitian menunjukkan bahwa perceived stress yang dirasakan berkorelasi positif dengan teacher burnout, dan berkorelasi negatif dengan self-efficacy. Selain itu, self-efficacy dan teacher burnout memiliki korelasi negatif. Sumbangan masing-masing variabel bebas terhadap variabel tergantung berdasarkan hasil output model summary analisis regresi sederhana dijelaskan pada tabel 5 .

\section{Tabel 5}

Nilai Sumbangan Variabel Bebas Terhadap Tergantung

\begin{tabular}{cc}
\hline Variabel & R \\
\hline Perceived stress terhadap teacher burnout & 0,923 \\
\hline Self-efficacy terhadap teacher burnout & 0,754 \\
\hline
\end{tabular}


Berdasarkan tabel 5, didapatkan hasil nilai koefisien determinasi perceived stress terhadap teacher burnout di Jakarta pada masa pandemi Covid-19 sebesar 0,923 artinya 92,3\% variabel teacher burnout dapat dijelaskan oleh variabel perceived stress dan sisanya 7,7\% dijelaskan oleh variabel lain yang tidak diteliti dalam penelitian ini. Sedangkan nilai koefisien determinasi self-efficacy terhadap teacher burnout guru TK di Jakarta pada masa pandemi Covid-19 sebesar 0,754 artinya $75,4 \%$ variabel teacher burnout dapat dijelaskan oleh variabel self-efficacy dan sisanya $24,6 \%$ dijelaskan oleh variabel lain yang tidak diteliti dalam penelitian ini.

Hipotesis yang menyatakan bahwa terdapat peran perceived stress dan self-efficacy terhadap teacher burnout teruji benar (diterima) secara empiris yang ditunjukkan dengan nilai $\mathrm{r}$ sebesar 92,7\% secara signifikan. Dengan demikian uji logis (hipotesis) dan uji empiris (uji data dari lapangan), hasilnya saling menguatkan. Hasil penelitian ini sesuai dengan penelitian yang pernah dilakukan oleh Schwarzer dan Hallum (2008) dengan tingkat kontribusi perceived stress dan selfefficacy memiliki pengaruh yang sangat tinggi yaitu $84 \%$ terhadap burnout. Untuk kontribusi stress terhadap burnout penelitian ini didukung oleh penelitian Bertoret (2009), dengan kontribusi sebesar $71 \%$ pada dimensi Reduced Personal Accomplishment, 45\% pada dimensi Emotional Exhaustion dan $21 \%$ pada dimensi Depersonalization. Sedangkan kontribusi self-efficacy terhadap burnout penelitian ini didukung oleh penelitian Consiglio et al. (2013), dengan kontribusi tinggi $\left(\mathrm{R}^{2}\right)$ 63\% untuk individu (individual-level model) dan bahkan mencapai kontribusi tinggi $\left(\mathrm{R}^{2}\right)$ 91\% untuk peran self-efficacy terhadap burnout secara kelompok/tim (team-level model). Perbedaan kontribusi dan tingkat burnout, dapat dimungkinkan karena pengaturan pekerjaan, faktor sosial budaya, ukuran penilaian yang berbeda atau kriteria yang berbeda pada pengukuran burnout di tiap-tiap negara (Li et al., 2020).

Sesuai dengan pendapat Gani dan Amalia (2018), jika koefisien determinasi yang diperoleh dari jenis data ini telah berada di atas $20 \%$ maka hasil penelitian sudah cukup layak untuk dijadikan sebagai alat analisis dan estimasi.

Selain itu, penelitian ini sejalan dengan penelitian-penelitian sebelumnya, (Herman et al., 2017; Li et al, 2020; Maryati \& Mustika, 2016; Wang et.al, 2015; Yu et.al., 2015; Zhu et al, 2018). Dalam beberapa hasil penelitian terdahulu terdapat hubungan independen antara perceived stress dan teacher burnout pada guru.

Perceived stress telah diidentifikasi sebagai salah satu penyebab langsung teacher burnout di kalangan guru (Yu et al., 2015). Pada kondisi pandemi Covid-19 menunjukkan bahwa masih terdapat guru TK yang belum siap dalam menghadapi perubahan lingkungan dan metode pembelajaran, padahal kesiapan guru merupakan hal penting, karena guru merupakan seseorang yang memberikan pengaruh terhadap keberhasilan anak dalam pembelajaran.

Guru TK, menurut Minicozzi (2016) selama ini memiliki beban yang lebih sulit dan banyak dalam mempersiapkan pembelajaran dan perkembangan anak usia dini (Minicozzi, 2016 dalam Ayuni et al., 2020). Dampak dari ketidaksiapan proses pembelajaran jarak jauh pada guru TK memunculkan perasaan kurang mendapatkan dukungan, cepat merasa lelah secara fisik, mengalami kecemasan berlebihan, sulit beristirahat/tidur, menurunnya daya tahan tubuh (mudah sakit), perubahan suasana hati yang cepat (mood swing), malas berinteraksi dengan orang lain serta mengalami penurunan baik secara prestasi maupun kompetensi. 
Gambaran kondisi di atas sesuai pendapat yang disampaikan Cohen et al. (1983), yang mengatakan bahwa perceived stress merupakan respon terhadap peristiwa yang tidak terduga, tidak terkontrol, berlebihan hingga mengancam dan berbentuk emosional 481 andemic yang berefek secara psikis serta psikologis dikarenakan beberapa faktor.

Faktor tersebut adalah faktor lingkungan ataupun psikologis. Hal ini sejalan dengan data empiris yang ditemukan dalam penelitian ini, 481andem guru mampu mengatasi perceived stress yang mereka alami, mereka akan lebih terhindar dari gejala teacher burnout. Sebaliknya 481 andem guru TK pada masa 481 andemic Covid-19 mengalami serangkaian peristiwa dan tuntutan dari lingkungannya yang membuat dirinya tertekan dan memberikan respon emosional 481 andemic, guru TK cenderung mengembangkan perceived stress yang lebih tinggi dan mengalami sindrom teacher burnout pada pekerjaan mereka.

Pada penelitian Wang et al. (2015), telah dilaporkan bahwa self-efficacy memprediksi secara 481andemic481481t gejala teacher burnout. Lebih khusus lagi, guru dengan self-efficacy yang lebih kuat terlihat dalam kemampuan mereka untuk melibatkan siswanya dalam pembelajaran, dan pada tingkat yang lebih rendah, mengelola kenakalan siswa dan kegiatan kelas, melaporkan tidak hanya kepuasan kerja yang lebih tinggi dan teacher burnout yan rendah, tetapi juga gejala penyakit yang lebih jarang (Wang et al., 2015).

Self-efficacy merupakan keyakinan individu mengenai kemampuan dirinya dalam melakukan tugas atau 481andemic yang diperlukan untuk mencapai hasil tertentu (Bandura, 1997). Hal ini sejalan dengan data empiris yang ditemukan dalam penelitian ini, 481andem guru memiliki selfefficacy yang tinggi mereka bisa menghadapi semua tantangan perubahan (termasuk tuntutan pembelajaran dan pola hubungan sosial) terkait pekerjaan yang diberlakukan pada masa 481andemic Covid-19, dan guru TK akan memiliki sikap yang positif terhadap pekerjaan mereka dan ini akan melindungi mereka dari teacher burnout, sebaliknya guru yang memiliki self-efficacy rendah, akan rentan mengalami teacher burnout. Pada penelitian ini guru TK memiliki tingkat self-efficacy yang rendah.

Perceived stress dan self-efficacy juga diketahui secara bersama-sama memengaruhi teacher burnout. Hal ini sejalan dengan data empiris yang ditemukan dalam penelitian menunjukkan 481 andem tingkat perceived stress tinggi, dan self-efficacy rendah memengaruhi tingkat teacher burnout guru TK pada masa 481 andemic Covid-19 menjadi tinggi dan sebaliknya, 481 andem tingkat perceived stress rendah, dan self-efficacy tinggi memengaruhi tingkat teacher burnout guru TK menjadi rendah pada masa 481 andemic Covid-19. Hal ini sejalan dengan temuan studi dari Wang et al. (2015), yang melaporkan hasil penelitiannya bahwa stress pada guru tidak hanya menjadi produk sampingan dari self-efficacy tapi mampu berkontribusi secara bersama-sama dan 481 andemic481481t terhadap teacher burnout.

Pertimbangan lain yang bisa menjadi faktor 481 andemic481 kuat dari peran perceived stress dan self-efficacy terhadap munculnya teacher burnout adalah faktor situasional khususnya pada masa 481 andemic Covid-19 yang secara langsung telah merubah situasi kerja guru TK. Sesuai dengan hasil penelitian Maslach et al. (2001) yang menyebutkan bahwa burnout sebagai pengalaman individu yang dikhususkan untuk konteks pekerjaan, telah dibuktikan melalui penelitian selama 25 tahun terakhir mempertahankan fokus yang konsisten pada faktor situasional di lingkungan kerja sebagai korelasi utama dari munculnya fenomena burnout pada individu. 


\section{KESIMPULAN DAN SARAN}

Berdasarkan penelitian ini, peneliti dapat menyimpulkan beberapa penjelasan sebagai berikut: (a) ada peran yang sangat signifikan antara perceived stress dan self-efficacy terhadap teacher burnout guru TK di Jakarta pada masa pandemi Covid-19. Semakin tinggi perceived stress maka semakin tinggi teacher burnout, sebaliknya semakin tinggi self efficacy maka semakin rendah teacher burnout; (b) terdapat peran positif sangat signifikan antara perceived stress terhadap teacher burnout guru TK di Jakarta pada masa pandemi Covid-19. Semakin tinggi perceived stress maka semakin tinggi teacher burnout dan semakin rendah perceived stress maka semakin rendah teacher burnout; (c) terdapat peran negatif yang sangat signifikan antara self-efficacy terhadap teacher burnout guru TK di Jakarta pada masa pandemi Covid-19. Semakin tinggi self-efficacy maka semakin rendah teacher burnout, sebaliknya semakin rendah self-efficacy maka semakin tinggi teacher burnout guru TK di Jakarta pada masa pandemi Covid-19. Di dalam studi ini kedua variabel bebas secara keseluruhan memiliki pengaruh sebesar 92,7\% terhadap teacher burnout. Terdapat 7,3\% sumbangan dari variabel lain yang belum diketahui. Kepada para peneliti selanjutnya yang berminat untuk melakukan penelitian dengan tema teacher burnout dapat menggali variabel lainnya. Penelitian ini juga dibatasi oleh waktu, biaya, dan terutama kondisi pandemi yang saat pengambilan data dilakukan sedang berlangsung, sehingga pemenuhan jumlah responden belum mencapai jumlah yang diharapkan. Sampel mungkin tidak representatif karena ini adalah kuisioner online, hanya guru yang memiliki akses internet dan akses ke komunitas pendidikan di jejaring sosial yang berpartisipasi dalam penelitian ini. Guru yang mengakses kuisioner online memiliki tingkat literasi perangkat digital tertentu. Diasumsikan bahwa guru yang telah berpartisipasi dalam penelitian sangat termotivasi karena partisipasi mereka dalam kelompok untuk pengembangan profesional. Hasilnya mungkin akan berbeda jika populasi yang lebih luas dimasukkan dan penelitian dilakukan bukan pada masa pandemi Covid-19.

\section{Ucapan Terima Kasih (Acknowledgement)}

Ucapan terimakasih dalam penelitian ini penulis tujukan kepada Almh. H.M., fakultas psikologi program studi magister psikologi sains UNTAR, pengurus organisasi Ikatan Guru Taman KanakKanak (IGTK) DKI Jakarta, seluruh Kepala TK di wilayah DKI Jakarta dan semua rekan sejawat Guru TK di Jakarta yang telah mendukung dan berpartisipasi dalam penelitian ini.

\section{REFERENSI}

Ayuni, D., Marini, T., Fauziddin, M., \& Pahrul, Y. (2020). Kesiapan guru TK menghadapi pembelajaran daring masa pandemi Covid-19. Jurnal Obsesi: PAUD, 5(1), 414-421.

Bandura, A. (Ed.). (1995). Self-efficacy in changing societies. Cambridge university press.

Bertoret, F. D. (2009). Self-efficacy, school resources, job stress and burnout among Spanish primary and secondary school teacher. Educational Psychology, 29, 45-68.

Cheng, M. N. (2008). Job stress, self-efficacy, burnout, and intention to leave among kindergarten teachers in Taiwan. Lynn University.

Cohen, S., Kamarck, T., \& Mermelstein, R. (1983). A global measure of perceived stress. Journal of health and social behavior, 385-396.

Cohen, S., Janicki-deverts, D., \& Miller, G. E. (2007). Psychological stress and disease. JAMA, 298(14), 1685-1687.

Consiglio, C., Borgogni, L., Alessandri, G., \& Schaufeli, W. B. (2013). Does self-efficacy matter for burnout and sickness absenteeism? The mediating role of demands and resources at the individual and team levels. Work \& Stress, 27(1), 22-42. 
Dewi, T. T. U., Tiatri, S., \& Mularsih, H. (2020). Peran pengetahuan awal tentang anak berkebutuhan khusus dan efikasi guru terhadap sikap guru pada pendidikan inklusif. Jurnal Muara Ilmu Sosial, Humaniora, dan Seni, 4(2), 304-314.

Gani, I., \& Amalia, S. (2018). Alat analisis data: Aplikasi statistik untuk penelitian bidang ekonomi dan sosial. Penerbit Andi.

Gravetter, F. J., \& Forzano, L. B. (2010). Research methods for the behavioral sciences (Gravetter). Belmont: Cengage Learning.

Hartawati, D., \& Mariyanti, S. (2013). Hubungan antara self-efficacy dengan burnout pada pengajar taman kanak-kanak sekolah "X" di Jakarta. Jurnal Psikologi Esa Unggul, 12(2), 54-60.

Herman, K. C., Hickmon-Rosa, J. E., \& Reinke, W. M. (2018). Empirically derived profiles of teacher stress, burnout, self-efficacy, and coping and associated student outcomes. Journal of Positive Behavior Interventions, 20(2), 90-100.

Husna, M. A. (2020). Guru PAUD hadapi permasalahan kompleks selama pandemi, orang tua tak siap hadapi pembelajaran daring. https://jogja.tribunnews.com/2020/07/18/gurupaud-hadapi-permasalahan-kompleks-selama-pandemi-orang-tua-tak-siap-hadapi pembelajaran-daring

Li, S., Li, Y., Lv, H., Jiang, R., Zhao, P., Zheng, X., Wang, L., Li, J., \& Mao, F. (2020). The prevalence and correlates of burnout among Chinese preschool teachers. BMC public health, 20(1), 160.

Maryati, D. S., \& Mustika, P. G. (2016). The effect of self-efficacy on burnout mediated by stress among kindergarten teachers in Indonesia. In 6th International Conference on Educational, Management, Administration and Leadership. Atlantis Press.

Maslach, C., Jackson, S. E., \& Leiter, M. P. (1996). MBI: Maslach burnout inventory. CPP, Incorporated.

Maslach, C., \& Leiter, M. P. (2008). Early predictors of job burnout and engagement. Journal of applied psychology, 93(3), 498.

Maslach, C., Schaufeli, W. B., \& Leiter, M. P. (2001). Job burnout. Annual review of psychology, 52(1), 397-422.

McLean, D., Eklund, K., Kilgus, S. P., \& Burns, M. K. (2019). Influence of teacher burnout and self-efficacy on teacher-related variance in social-emotional and behavioral screening scores. School Psychology, 34(5), 503.

Minicozzi, L. L. (2016). The garden is thorny: Teaching kindergarten in the age of accountability. Global Studies of Childhood, 6(3), 299-310.

Nagasawa, M., \& Tarrant, K. (2020). Who will care for the early care and education workforce? COVID-19 and the need to support early childhood educators' EWB. New York Early Childhood Professional Development Institute, CUNY. https://educate.bankstreet.edu/cgi/viewcontent.cgi?article $=1000 \&$ context=sc

Schaufasher, D. (2020, Juni 2). Educators feeling stress, anxious, overwhelmed and capable. The Journal. https://thejournal.com/articles/2020/06/02/survey-teachers-feeling-stressedanxious-overwhelmed-and-capable.aspx

Schwarzer, R., \& Hallum, S. (2008). Perceived teacher self-efficacy as a predictor of job stress and burnout: Mediation analyses. Applied psychology, 57, 152-171.

Schwarzer, R., \& Jerusalem, M (1995). Generalized self-efficacy scale. NFER-NELSON.

Sugiyono, S. (2010). Metode penelitian kuantitatif dan kualitatif dan R\&D. Alfabeta.

Wang, H., Hall, N. C., \& Rahimi, S. (2015). Self-efficacy and causal attributions in teachers: Effects on burnout, job satisfaction, illness, and quitting intentions. Teaching and

Teacher Education, 47, 120-130. 
Zhu, M., Liu, Q., Fu, Y., Yang, T., Zhang, X., \& Shi, J. (2018). The relationship between teacher self-concept, teacher efficacy and burnout. Teachers and Teaching, 24(7), 788-80. 